\title{
FutureThink
}

\section{Strategic Imperatives That Will Drive Healthcare in a Networked World}

\author{
RICK DURIG
}

\section{Why the INTERnet Is A "DisRUPtive TeChNOlogy" in Healthcare}

The two most notable attributes of the Internet and its impact on healthcare are how early on we are in terms of its development and deployment and, at the same time, the unprecedented speed with which the technology is transforming industry after industry.

We are truly in the "Kitty Hawk" era of the Internet, as Jeff Bezos, Chairman of Amazon.com, claims. It's so early in the deployment of the technology, in fact, that virtually every prediction made about its growth, impact and deployment is underestimated. Internet years are referred to as three-month periods of time in which new entrants are discovered and new business models emerge. The latter is the subject of a later section. Suffice to say now that the concept of "business models" is replacing the concept of product models/cycles. In fact, the traditional notion of a "product life cycle" is being replaced with a concept referred to as "business model life cycle." The technology, and its ubiquitous presence in our lives, is moving so fast that actual business models - or ways of making money - are changing as rapidly as products changed during the industrial development era.

The most striking evidence of the speed with which the Internet, and its changing expectations, is reshaping the global business landscape is its adoption rate. It took radio 38 years to reach 50 million users, television 13 years, cable television 10 years, and the Internet five years!

The lesson here is clear: Organizations must stop thinking of the Internet and its related networked technologies as technologies in and of themselves and start looking at how these technologies are transforming business models. Technology does not in and of itself transform industries customers and their expectations do. It will do us well to understand what new healthcare customers will emerge and what they will expect from us in terms of the use and implementation of this technology.

Before we examine the impact of customers' expectations, let's first examine why so many experts regard the Internet as a "disruptive technology." Clayton Christensen first developed the term disruptive technology in his best-selling book The Innovator's Dilemma. The term refers to the fact that some technologies, even leaps in technology, exist merely to sustain an existing technology, making the products and services more convenient, better, faster and cheaper for current customers. Every once in a while, however, a disruptive technology comes along that everyone in the mainstream industry ignores because it typically does not meet the expectations of the current mass market - for example, electric cars, or the first emergence of the HMO model, or healthcare information delivered over the Internet. (It is interesting to note that of the top ten healthcare websites only two are related to a current player in the marketplace - Mayo and United Healthcare.) In sum, a new technology is disruptive if it changes two critical dimensions of an organization's business model: its customer's "value net" - that is, what the customer (often a new customer) values or "needs" in the use of the new product or technology - and the manner in which the product is delivered to the customer - what this author refers to as the "how." 
Essentially, understanding an organization's business model consists of answering four basic questions regarding its fundamental components:

1. What function does the organization perform - customer functions, products, services?

This involves defining the needs the organization is attempting to fill by describing the products and services it delivers to its customers. In its simplest form this dimension describes what customers pay the organization for doing, delivering or producing.

2. For whom does the organization perform this function customers/clients?

This involves defining specifically which part of the market the organization is attempting to serve. Few, if any, organizations in the Internet age are attempting to serve everybody, and in any event, not everybody has the same needs.

3. How does the organization go about performing this function?

The "how" is concerned with answering the question of how the organization will attempt to achieve its goals. For example, what technologies will be used in meeting the needs identified in its market? The "how" may involve marketing strategies such as providing innovative products or marketing itself as a low cost producer. Or it may involve a distinct distribution strategy such as providing noappointment doctor visits in shopping malls. Another important aspect of "how" involves the consideration of acquisitions, mergers or partnerships. If, for example, growth or movement into new lines of business becomes a significant part of the strategic plan, then such growth or movement can often be most readily obtained through acquisition or merger and it should be included as part of the "how" portion of an organization's core business model.

\section{What need does the organization satisfy?}

This describes the customer's value net. It describes what is important in terms of price, feature, function, convenience, and so on. In the age of the Internet this is the most critical aspect of an organization's core business proposition or business model proposition because it is a moving target.

The essential point in discussing these elements of an organization's business model is the fact that the Internet, along with a few other critical industry dynamics, is rapidly changing the definitions of each of these elements in the healthcare space. In the next three to five years we will see a dramatic change in each of the aforementioned four dimensions. In particular, the
Internet will dramatically transform both the customers we serve and their attendant value nets and the manner in which we deliver those services, or the "how."

To further define and understand how this will happen, we tested this hypothesis with substantial industry research. That research and its findings are the subject of the next section.

\section{Watershed Study in Healthcare}

On an annual basis the IBM Corporation embarks upon a series of industry-specific studies that examine the trends and impacts of major factors affecting a particular industry. We recently concluded our analysis of the healthcare industry and found that some dramatic changes are underway. What follows is a brief overview of the study's methods, objectives and overall findings.

Clearly there are major changes sweeping through healthcare. While most of these changes are undeniable, gauging the waves will be the most difficult task for senior mangers and healthcare administrators. Understanding, with a level of precision at least $1 \%$ better than your competition, the timing of these changes, how big they will be, what kind of impact they will have and the consequences for your organization's strategy will be the true determinants of success in this brave new world.

The objectives for the study were relatively straightforward, but far-reaching in their analysis and conclusions. We wanted to achieve the following objectives:

- Create a vision for industry transformation.

- Assess the role of e-business as a driver or enabler of change and a source of future competitive advantage.

The deliverables for the study were as follows:

- Determine changes in "ecosystem" structure, relationships.

- Discover processes where e-business has a high impact.

- Determine key success factors: business models, infrastructure.

The methodology used in the study involved interviews and survey responses from over 70 companies across the spectrum of healthcare participants, including payers, providers, pharmaceuticals and medical device manufacturers. To analyze the results the team employed a scenario planning process in which they identified what we refer to as "e-critical" drivers. These drivers became the dimensions for the scenario planning output.

The two key drivers that were analyzed in the study and that form the basis of the scenario planning process include:

- Knowledge efficiency: Defined as the ease, convenience and speed with which information is delivered and managed by healthcare participants. In addition, it measured the degree to which standardization in the clinical delivery of healthcare has occurred. 
- Consumerism: Defined as the degree to which the consumer is both empowered with valid information and the degree to which the consumer controls the actual spending of the healthcare dollar.

The criteria that was used for selecting these dimensions included the following:

- High degree of impact in the industry.

- High degree of uncertainty with respect to speed, breadth and timing.

- Degree to which they were independent of one another.

- How broadly applicable the dimensions are to the industry.

The study resulted in a four-quadrant scenario analysis with consumerism on the horizontal axis and knowledge efficiency on the vertical axis as depicted in Figure 1.

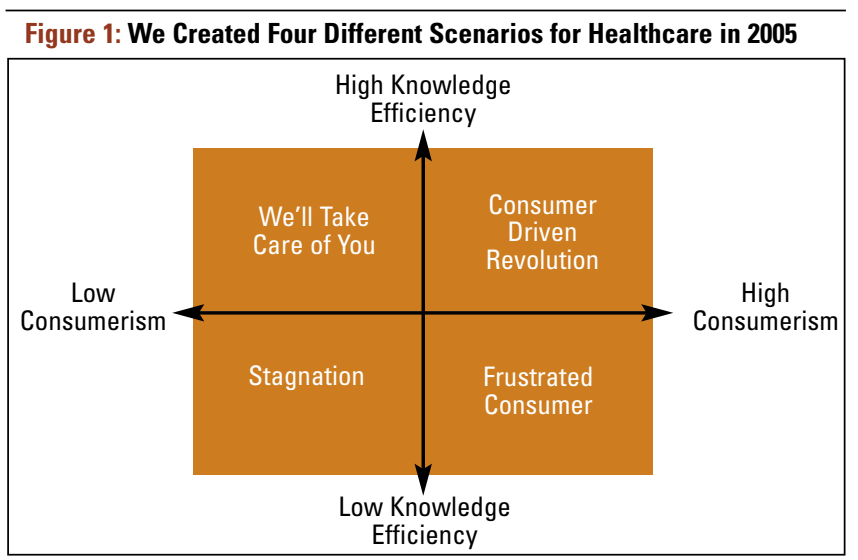

Clearly the research and subsequent analysis of the data resulted in an overwhelming consensus that the two change dimensions taken together represent the potential for a truly market-driven healthcare economy to emerge. However, it is important to note that while the consensus opinion is that healthcare will move to the upper right quadrant of the grid, many conditions have to co-exist for that to occur, and the other scenarios are equally as likely if these conditions don't materialize.

In general we see two key things that have to happen in order for the market to reach the upper right quadrant of the scenario analysis depicted in Figure 1. First, we see the employers, gradually at first but then more dramatically by 2005 , disintermediating themselves from the healthcare decisionmaking process. This trend will likely follow the same paths that pension plan contributions have pioneered over the last decade and a half. Once the consumer is firmly in control of the healthcare dollar, we predict that there will be an unleashing of an entirely different kind of demand, discussed more fully in the next section on strategic imperatives. Second, the industry has to learn how to separate the information value net from the physical value net. Figure 2 depicts the dramatic difference between the two kinds of value nets.

\begin{tabular}{l}
\hline Figure 2: Separating the Information from the Product Can Generate \\
New Value. \\
$\begin{array}{l}\text { Information Value Net } \\
\text { - Information and knowledge flows disaggregated from physical } \\
\text { - Business intelligence } \\
\text { - Major role for Knowledge Management } \\
\text { Physical Value Net } \\
\text { - Material and process flows along the supply chain for suppliers } \\
\text { - Medical care delivery for provider/payers }\end{array}$
\end{tabular}

In order for healthcare to thrive in this consumer-driven economy it will have to learn to value its knowledge and information separate from the physical delivery of the product itself. Ultimately the activities associated with these two distinct value nets will develop their own pricing mechanisms as well. Today only the most innovative players understand this important separation, and they are using the power of the Internet to design entirely new business models and value propositions to the consumer. The extent to which current players understand this "disruptive" approach and react to it will be their ultimate measure of success.

\section{The Seven Strategic Imperatives}

As a result of the watershed study we created some key imperatives that all healthcare executives will need to pay attention to in order to survive and thrive in this new networked and wired world. The following describes each of the imperatives and provides an overview of the implications each will have on corporate strategies.

Imperative One: The economic model for healthcare will change. Everyone agrees that the current state is not what we would invent if we started over. By the same token, for all the failings of our current system we don't want to throw the baby out with the bath water. How do we save what is admired about our healthcare system and rid us of what is not desirable? The answer lies in the changing of the economic model. As long as healthcare remains ostensibly a commercial enterprise (that is, not totally government controlled) the system must become more responsive to the consumer. We do not believe that will happen until the consumer takes control of the dollar and the underlying economic model of how healthcare is financed is fundamentally changed. We need to move from a risk-based environment to a financial management environment.

Imperative Two: Consolidation hasn't even begun - grow or die. The problem with consolidation is that we haven't consolidated the right things. Even with all the recent mergers and acquisitions we haven't acquired the commensurate productiv- 
ity gains we have come to expect from other industries. All we've consolidated is bricks and mortar and stock. In order for the industry to be in a position to respond to the consumer we have to consolidate processes and standardize practices. On the payer side that means reducing the healthcare transaction to its simplest form. On the provider side it means determining if you will be an information value net player or a physical value net player and subsequently becoming what Regina Herzlinger of the Harvard Business School calls in Market Driven Health Care a "focused factory" in a particular area of specialty or expertise.

\section{Imperative Three: Consumers will take back control of their healthcare dollar.}

This imperative is the backbone of the remaining imperatives. Clearly the consumer will transform the industry in ways that most executives in healthcare have not yet even imagined. Most of our work and assumptions in this area are drawn from the excellent work and insights derived from Regina Herzlinger's work in Market Driven Health Care. (For purposes of brevity we will not review her hypothesis in this document. Instead, we refer readers to Ms. Herzlinger's work.)

\section{Imperative Four: Cost concerns will begin to fade and be} replaced by a new value proposition.

As the consumer assumes command of the healthcare dollar, the previous emphasis on cost, cost, cost will be replaced with a more robust view of value that is tied to the entirety of the healthcare experience rather than just the cost of "coverage." Firms engaged in the healthcare trade will need to understand a total customer value chain with the same terms other industries have had to compete under for years. "Customer relationship management" (CRM) will take on a whole new dimension when the customer becomes the actual payer and recipient of healthcare services simultaneously. We don't even have to look too far outside the healthcare field to see how the customer has transformed other industry segments. Take dental services and eyewear, for example. These are segments of the health industry that long ago had to learn to compete for consumer's dollars and preferences. Compare the variety, convenience and price transparency of your recent purchases of those services to your most recent doctor's visit, and the differences and impact the consumer will have will become clear.

\section{Imperative Five: Quality will mean something different to the consumer.}

The manner in which we measure quality in healthcare today will be dramatically impacted by the advent of the empowered, informed consumer. Outcome analysis, the core of HEDIS and other quality measures, will be but one of many inputs to the consumer's perception of quality. But the dimensions we outlined above will transform the notion of quality itself. Outcome analysis will become the baseline bar, or what we refer to as "tablestakes" into the healthcare game. Differentiation will not come about by the traditional outcome measures because, as medicine standardizes, the appreciable differentiation in that dimension of quality will be negligible to the consumer. What will create differentiation in tomorrow's healthcare economy? It will be the consumer's traditional notion of value and quality, which is measured more by factors such as convenience, value for price, ease of use, speed, etc. Without an understanding of how to implement these dimensions of quality, current stakeholders will not be able to compete successfully in either the information value net or the physical value net.

\section{Imperative Six: Mass customization of healthcare services will occur.} The reason we have not seen the dramatic increases in productivity in healthcare that we have witnessed in other industries is a function of two interactive dimensions. First, we still treat healthcare as a locally delivered phenomenon. This severely limits the notion of capacity for an individual provider of care to a single geographic region. That capacity is further constrained by the limitations of the brick and mortar locations that can be built and accessed by the consumer. Second, we have not seen the kind of specialization and niche facilities that then grow into large-scale operations as we have seen in other industries such as retailing (e.g., Home Depot) and financial services (e.g., Charles Schwabb).

The notion of mass customization is directly linked to the standardization of medicine. Without standardized procedures, processes and approaches, none of the above-mentioned examples could have grown into the large-scale efficient operations they have become. Regina Herzlinger refers to these emerging healthcare systems as "focused factories." Some of the current providers and provincial thinkers within the healthcare industry may not take kindly to these analogies of retailing, and others to the "science" of medicine. Nonetheless, and make no mistake about it, these changes are underway, we are powerless to stop them, and we must learn to adapt our enterprises to them. Otherwise we risk a rapid extinction.

\section{Imperative Seven: Technology won't change the way healthcare is delivered.}

With all the hype the Internet has received including sky-high valuations, instant millionaires and industry transformation, we must recognize that the technology itself is just a tool to solve a business problem. The problem is the advent of the informed, empowered consumer. The Internet is just rushing the pace of this inevitable change. The lesson here is clear. Stop worrying about your Internet or "e-business" strategy and start worrying about your business model strategy. Your customers 
and the way you need to serve them are about to change dramatically, before your very eyes. Are you prepared for this transformation, or are your eyes wide shut?

\section{Emerging Business Models in the Networked WorLd OF HealthCARE}

Figure 3 outlines the questions to be addressed in this section.

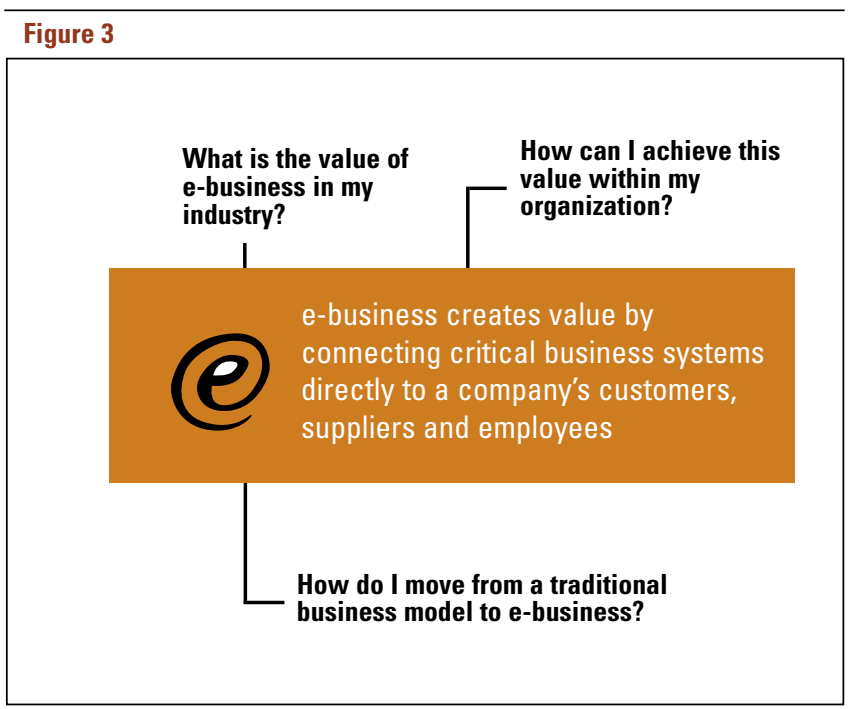

The Internet has ushered in a variety of new and emerging business models that are taking virtually all industries by storm. We have organized the basic components of the types of e-business "plays," as they are often called, in healthcare and categorized the different plays in terms of their various attributes, including the desired end game, revenue sources, critical success factors and metrics commonly used for each. Figure 4 depicts these attributes in terms of the five key plays we see emerging in the marketplace - connectivity, commerce, content, community and clinical applications.

\section{Health E-Business Models}

While Figure 4 is not meant to be an exhaustive representation of all the possibilities within a given e-business play, it does illustrate the important differences between the varying strategic intents of each. It is difficult for an existing organization to try to position itself to be good at all five plays at once or even more than one play at once for that matter. The point of the representation is for healthcare participants to pick a starting point and get focused. This focused requirement is not necessary for the traditional "stick to your knitting" reasons, but because of the necessity of speed to market that these various Internet strategies demand. We encourage all healthcare executives to evaluate their current and future e-business plays in this unique context and get going while recognizing that this

\begin{tabular}{|c|c|c|c|c|}
\hline \multicolumn{5}{|c|}{ Figure 4: Differences between Varying Strategic Intents } \\
\hline BUSINESS AREA & END GAME & REVENUE SOURCES & CSF's & METRICS \\
\hline Connectivity & $\begin{array}{l}\text {-MD eyeballs } \\
\text { - System Integration } \\
\text {-EDI } \\
\text {-EMRs }\end{array}$ & $\begin{array}{l}\text { - Transaction fees } \\
\text {-Subscriptions } \\
\text { E-commerce revenues }\end{array}$ & $\begin{array}{l}\text {-Data Security } \\
\text { - System Integration } \\
\text { - User Adoption }\end{array}$ & $\begin{array}{l}\text { - Transactions } \\
\text { - Claim cost } \\
\text { - Claims processing } \\
\text { efficiency }\end{array}$ \\
\hline Commerce & $\begin{array}{l}\text { - Critical mass } \\
\text { - Customer acquisitions } \\
\text { - Lower cost improved } \\
\text { produce information }\end{array}$ & $\begin{array}{l}\text { - Transactions } \\
\text { - Listing fees } \\
\text { - Supplier rebates } \\
\text { - Referral fees } \\
\text { - Advertising } \\
\text { - Sponsorships }\end{array}$ & $\begin{array}{l}\text { - Brand recognition } \\
\text {-Appropriate product } \\
\text { offering } \\
\text { - Fulfillment } \\
\text {-Data accuracy } \\
\text { - Security }\end{array}$ & $\begin{array}{l}\text { - Unique visitors } \\
\text { - Registered customers } \\
\text { and suppliers } \\
\text {-\# of transactions } \\
\text { - Size of transactions } \\
\text { - Payer relationships }\end{array}$ \\
\hline Content & $\begin{array}{l}\cdot \text { Reach } \\
\text {-Brand } \\
\text { - Mindshare }\end{array}$ & $\begin{array}{l}\text {-Advertising } \\
\text {-Sponsorships } \\
\text { - License fees } \\
\text { - Subscriptions }\end{array}$ & $\begin{array}{l}\text { - First mover } \\
\text {-Personalization features } \\
\text {-Partnerships }\end{array}$ & $\begin{array}{l}\text { - Unique visitors } \\
\text { - Time on site } \\
\text { - Clickthroughs } \\
\text {-Visitor demographics }\end{array}$ \\
\hline Community & $\begin{array}{l}\text { - Large target audience } \\
\text { - High participation levels } \\
\text {-High member usage }\end{array}$ & $\begin{array}{l}\text {-Advertising } \\
\text { - Sponsorships } \\
\text {-Data sales } \\
\text { - Subscriptions }\end{array}$ & $\begin{array}{l}\text {-Value-added services } \\
\text { - Quality advice and } \\
\text { information } \\
\text {-Moderated messaging } \\
\text {-Partnerships }\end{array}$ & $\begin{array}{l}\text { - Unique visitors } \\
\text { - Time on site(s) } \\
\text { - Paid subscriptions } \\
\text { - Member demographics }\end{array}$ \\
\hline Clinical Applications & $\begin{array}{l}\text { - Clinical acceptance } \\
\text {-Provider acceptance } \\
\text {-Payer acceptance } \\
\text {-Patient acceptance }\end{array}$ & $\begin{array}{l}\text {-Software sales } \\
\text { - Hardware sales } \\
\text {-Data sales } \\
\text { - Transaction fees }\end{array}$ & $\begin{array}{l}\text { - Market penetration } \\
\text {-Application relevance } \\
\text { - System compatibility } \\
\text { - Streamlines processes }\end{array}$ & $\begin{array}{l}\text { - Installed base } \\
\text { - Usage } \\
\text { - Market share }\end{array}$ \\
\hline
\end{tabular}


game will move quickly and understanding that where you begin might not be where you end up. Figure 5 provides some recent examples of healthcare plays in each of the abovementioned categories.
The notion of calculating the "cannibalization" effect sinks any possible rate of return gains, and the costs associated with not transforming the business model are rarely valued or thoroughly analyzed precisely because none of the traditional methods employed in such endeavours will work.

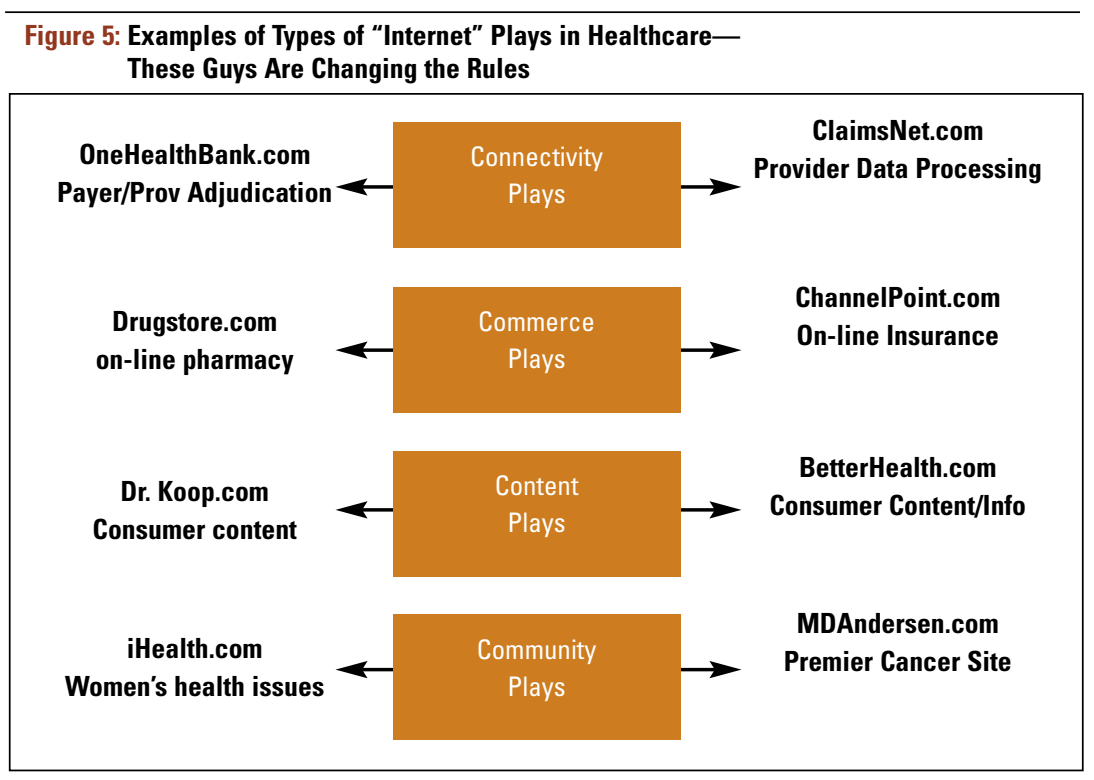

Finally, capital costs are too high for traditional firms trying to compete with start-ups. As seen time and again throughout the media, traditional firms have difficulty attaining the same $\mathrm{P} / \mathrm{E}$ multiples as startups. Healthcare executives must define what results are most important (mindshare? brand? customer relations?) and then target efforts to achieve that end game.

\section{LESSONS LEARNED AND THE IMPLICATIONS fOR Healthcare Participants/Stakeholders}

In summary, we believe that all healthcare participants must understand the following list of imperatives and begin the process of implementation immediately. Time is of the essence, as many players outside the healthcare space are salivating over a piece of this trillion-dollar-plus economy:

\section{Understanding ROI in These New Models}

It is important to understand that the traditional methods for measuring and monitoring ROI in this brave new world will not work any longer with these kinds of disruptive plays. Some of the differences are clear and are reflected in Table 1.

\begin{tabular}{l}
\hline Table 1: Traditional ROI model vs. the e-business ROI model \\
\begin{tabular}{|ll|}
\hline TRADITIONAL MODEL & E-BIZ MODEL \\
- ROI & - Market capitalization increase \\
- Return on assets & - Productivity \\
- Financial accounting ratios & -Decreased cycle times \\
& -Access to New Markets \\
& - Improved customer relations \\
& (intimacy, retention, profitability) \\
\hline
\end{tabular} \\
\hline
\end{tabular}

Traditional ROI does not work for e-business. There are no reliable benchmarks for similar businesses, and e-business is too new to accurately predict returns. In addition, first-mover advantages are hard to predict, and even the smallest changes in market/business strategy can have huge effects.

E-business timeframes tend to extend beyond normal legacy business ROI windows, whereas traditional ROI works where business efficiency increases or new markets open, but not where new business models are created.
- Understand your customers' value chain.

- Make strategic decisions about how you enable processes that enhance your customers' value chain.

- Stop enabling old processes and start thinking about a new business model for both you and your customers.

- Act quickly and decisively, but be prepared to change course without notice.

- Focus on scenario planning, not strategy.

- The bricks and mortar model won't last in its current form.

- Understand how knowledge can be valued and distributed. IQ

Rick Durig is a Principal in IBM's Healthcare Consulting Practice and is IBM's segment leader for consulting and services. He has over a decade of senior level management and consulting experience and is an expert in the change dynamics of the healthcare industry in North America.

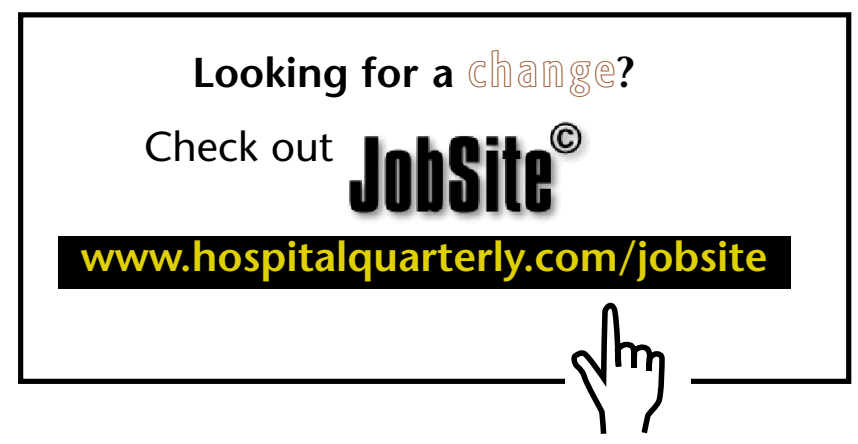

